\title{
Design Education and Multiculturalism
}

\author{
Keywords \\ Multiculturalism, Decolonizing design, Identity, Online education
}

Design education exists at the cross-disciplinary intersection of sociology, cognitive psychology, technology and material history. In India, as in many other countries which have experienced colonisation, the wave of decolonisation demands questioning the normative ways of knowing, doing and being. The idea of decolonisation is reflected upon as peeling off the layers of dogmas created by other cultures on existing ones. In the wake of decolonisation, there is a rising concern for plural and multicultural societies. The practise of living out day to day varies across the cultures and often ends up alienating or excluding multiplicity of voices. In today's context digital disruption, with added layers of social media, the concept of 'self' and the 'other', the idea of 'identity' has become a complex phenomenon equated with cultural studies. The case study shared through this paper is carried out with students of first year at NID Haryana, in their first year first semester of undergraduate programme, Bachelor in Design. Facilitating a course on Indian Society and Culture for design students, posed a pedagogical challenge to bring together diverse and eclectic approaches while training the students to deepen their understanding of their own subjective positions and exploring cultural narratives in which their design ought to function. The findings and discussion points are an outcome of the assignment attempted by the student during the module inputs 'Approaches to Indian Culture', structured using autoethnography research framework. The said assignment was introduced in the context of online education due to Covid -19 where students were encouraged to pay attention to their immediate home environment as a living cultural repository. The day-to-day cultural resources available to us often become invisibilised, in favour of tangible predefined ones like those of museums or tangible objects. The students were encouraged to look at being part of the cultural context, but still retain a distance from which they could question, interrogate and challenge some of the normative assumptions that come as part of belonging to the said cultural context. The paper discusses the need to become aware and situate oneself as a designer in the cultural context that has shaped his/her/their identity and intrinsic motivations. The aspirant designer was subjected to become aware of his/ her vulnerable position in the light of his newly acknowledged socio cultural context through the means of mapping cultural changes in his family over last three generations. This has been instrumental in initiating a journey to engage with cultural change with sensitivity, appreciate and become aware of the role of oneself in making conscious choices. Through this paper, we would like to investigate this process of decolonising the identity of the designer. The paper expands on complexity of aspects mapped by the students, their reflections and probes further on methods, approach that ought to be adopted in the process of declonising the designer. 